\title{
Influence of Acrylic Fibers Geometry on the Mechanical Performance of Fiber-Cement Composites
}

\author{
H. R. Pakravan, ${ }^{1}$ M. Jamshidi, ${ }^{2}$ M. Latif, ${ }^{3}$ F. Pacheco-Torgal ${ }^{4}$ \\ ${ }^{1}$ Department of Textile Engineering, Textile Excellence \& Research Centers, Amirkabir University of Technology, \\ Iran \\ ${ }^{2}$ Chemical Engineering Department, Polymer Group, Iran University of Science and Technology, Tehran, Iran \\ ${ }^{3}$ Textile Engineering Department, ATMT Research and Excellence (CENMIT) Centers, Amirkabir University of \\ Technology, Tehran, Iran \\ ${ }^{4}$ University of Minho, C-TAC Research Unit, Sustainable Construction Group, 4800-058 Guimarães, Portugal
}

Received 24 April 2011; accepted 22 June 2011

DOI 10.1002/app.36410

Published online in Wiley Online Library (wileyonlinelibrary.com).

\begin{abstract}
This article analyses the influence of acrylic fibers shape on the flexural behavior of cement composite. The fibers differ in their cross-sectional shapes due to the spinning process (wet-spun and dry-spun). The fibers were characterized by optical microscopy, and the shape factors were calculated on the basis of their geometric characteristics. Results showed that both types of acrylic fiber remarkably improved the flexural performance of the
\end{abstract}

composites. Wet-spun acrylic fibers lead to high flexural strength and toughness. It was found that by increasing the fibers' shape factor by a factor of $10 \%$, flexural strength and toughness increase to $26 \%$ and $23 \%$, respectively. (c) 2012 Wiley Periodicals, Inc. J Appl Polym Sci 000: 000-000, 2012

Key words: acrylic fiber; shape factor; cementitious composites; flexural strength

\section{INTRODUCTION}

The use of fibers as cement composites reinforcement has been found to be an effective and economical way to convert these materials into ductile products, ${ }^{1}$ well suited for structures subjected to seismic loads, bending and/or shear loads, and structures needed higher load-carrying capacity. ${ }^{2}$

Adding fibers to cement-based materials enhances both tensile strength and flexural toughness properties. ${ }^{3}$ Generally speaking, cracks arise in cementitious pastes during the hydration process (plastic shrinkage) or by external mechanical loads. Microcracks usually transform to macrocracks and then cause failure and fracture of the cement matrix. Fibers can control crack creation and crack propagation by energy absorption in the bridging actions of fibers. ${ }^{4}$ In the last decades, different fibers were used in cementitious materials. The most frequently were polymeric fibers (acrylic, 5,6 polyvinyl alcohol, 7,8 polyethylene, $^{9,10}$ polypropylene, ${ }^{1,12}$ and nylon ${ }^{13,14}$ ), natural cellulose (such as hardwood and softwood pulps ${ }^{15-17]}$ ), and inorganic fibers (asbestos, ${ }^{18,19}$ glass, ${ }^{20,21}$ and carbon $^{22,23}$ ). Nowadays, it is well known that the mechanical performance of fiber reinforced cementitious composites are influenced by fiber properties (type,

Correspondence to: M. Jamshidi (mjamshidi@iust.ac.ir).

Journal of Applied Polymer Science, Vol. 000, 000-000 (2012) (c) 2012 Wiley Periodicals, Inc. strength, stiffness, and Poisson's ratio), fiber geometry (surface and longitudinal shape), fiber volume content in the composite, their dispersion and the matrix properties (matrix strength, stiffness, and Poisson's ratio), and interface properties between fiber and cement matrix (adhesion, frictional and mechanical bond). ${ }^{24}$

The geometry of the fiber (crimp, hook, and indenting) influences the bonding of the fibers to cementitious materials by mechanical interlocking. ${ }^{25-27}$ This property affects the mechanical performance of cement composites and the resistance to crack opening and to crack propagation in composites. ${ }^{28-30}$ High fiber/matrix bonding leads to higher strength, ductility, fracture energy, and energy absorption capacity. ${ }^{31}$ The energy absorption has an important role regarding seismic loads and bending and/or shear loads. In this article, investigations related to the influence of the fibers shape on the flexural behavior of cement composites are presented.

\section{EXPERIMENTAL}

\section{Materials}

Portland cement Type I, manufactured by Tehran Cement Co. (Tehran, Iran), was used in this investigation. This study used wet- and dry-spun acrylic fibers produced by Iran Polyacryl Co (Isfahan, Iran). In this study, acrylic short fibers $(4-6 \mathrm{~mm})$ were used to reinforce the cement past. The acrylic fibers were based on acrylonitrile monomers, which contain at 

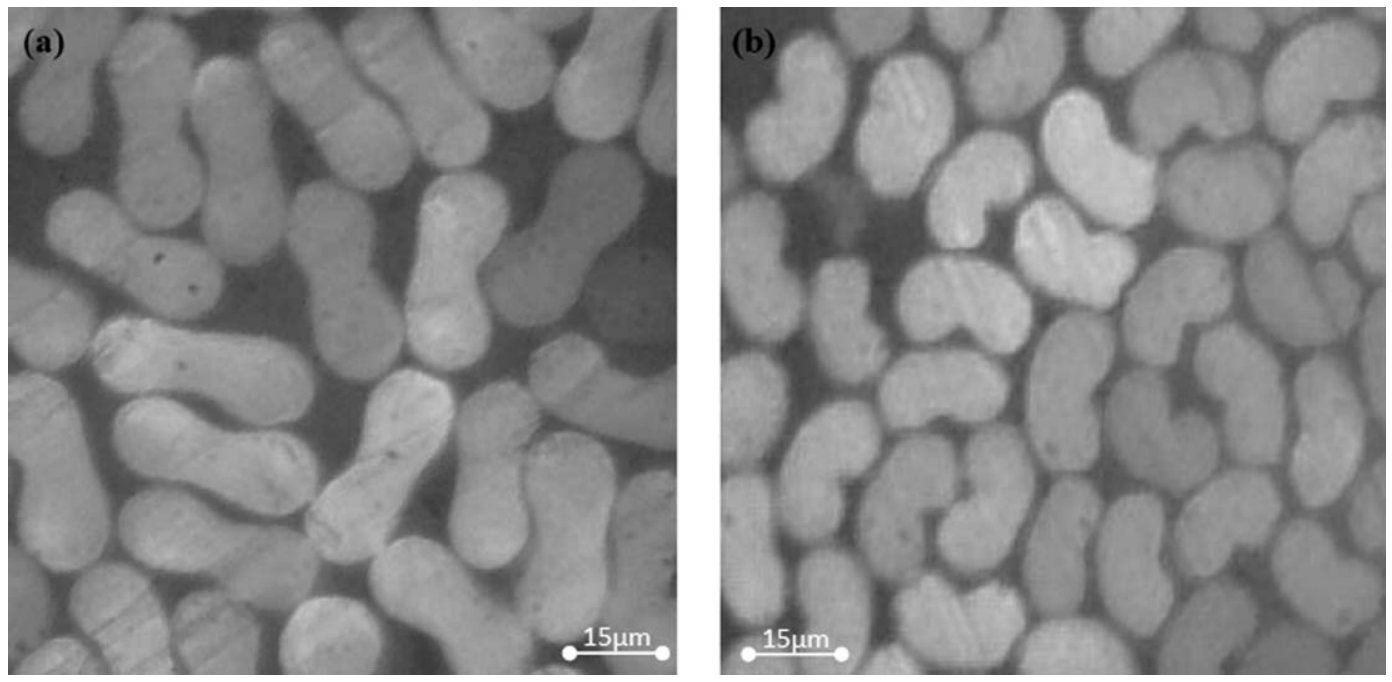

Figure 1 Typical cross-sectional shape for: (a) dry-spun acrylic fiber and (b) wet-spun acrylic fiber.

least $85 \%$ acrylonitrile. The cross-sections of the fibers were investigated by optical microscopy and the cross-section images of fibers are shown in Figure 1. It is evident that the wet-spun fibers have kidney-shaped cross-section, while the dry-spun fibers have dog-bone-shaped cross-section.

In solution spinning, the method in which fibers lose their solvent can produce different crosssectional shape. Dry-spinning, air or vapor air is used to evaporate the solvent, then the fibers' solidification occurs. In wet spinning, spinning solution is extruded into a precipitation bath in which the coagulation occurs by the diffusion of the solvent out of the thread. $^{32-33}$ In Figure 2, the schematic of both dryand wet-spinning methods were shown. Fibers' physical and mechanical properties were shown in Table I.

\section{Mix design}

The acrylic fibers were used at different volume percentages in cement paste. Table II shows the mix designs. After casting, the specimens were cured for
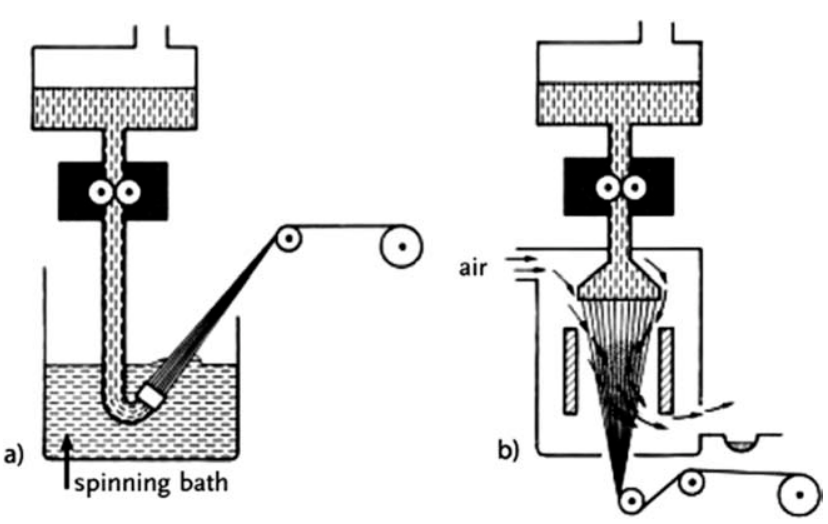

Figure 2 Schematic representation for the spinning process of the fibers: (a) wet process and (b) dry process.
28 days in a humidity chamber at the temperature of $23 \pm 2{ }^{\circ} \mathrm{C}$ and a $95 \pm 5 \% \mathrm{RH}$ (relative humidity). After the curing, the specimens were evaluated for flexural strength by the three-point load bearing machine, on the basis of the requirements of EN12467 standard.

\section{Specimen preparation}

Cement and water were mixed in a mixer for $2 \mathrm{~min}$ to produce a dilute suspension. Short acrylic fibers were introduced gradually into the mixture. The suspension containing the fibers was mixed for 5 min to achieve proper uniformity. Finally, the wet mixtures were cast into a special mold and dewatered by a vacuum pump. The dimension of the specimens was $280 \mathrm{~mm}$ (length) $\times 80 \mathrm{~mm}$ (width) $\times 8 \mathrm{~mm}$ (thickness). The three-point loading bearing tests were performed using a Tinus Olsen machine. The crosshead speed was $0.03 \mathrm{~mm} / \mathrm{min}$, and the span length was $160 \mathrm{~mm}$. During the test, the value of the load versus midspan deflection was recorded. In this system, the flexural strength was determined as following:

$$
\sigma=\frac{3 F K}{2 w h^{2}}
$$

in which $F, L, W$, and $h$ are the maximum load, span length, width of the specimen, and height of specimen, respectively.

TABLE I

Fibers Properties

\begin{tabular}{ccccc}
\hline $\begin{array}{c}\text { Fiber } \\
\text { type }\end{array}$ & $\begin{array}{c}\text { Linear } \\
\text { density } \\
(\text { dtex })\end{array}$ & $\begin{array}{c}\text { Tenacity } \\
(\text { cN/dtex })\end{array}$ & $\begin{array}{c}\text { Elongation } \\
(\%)\end{array}$ & $\begin{array}{c}\text { Modulus of } \\
\text { elasticity } \\
\text { (cN/dtex) }\end{array}$ \\
\hline Dry-spun & 14.40 & 2.88 & 45.56 & 50.45 \\
Wet-spun & 13.18 & 2.25 & 49.35 & 48.78 \\
\hline
\end{tabular}


TABLE II

Used Mix Designs

\begin{tabular}{lccc}
\hline \multicolumn{1}{c}{ Materials } & $\begin{array}{c}\text { Cement } \\
(\text { vol \%) }\end{array}$ & $\begin{array}{c}\text { Water } \\
(\text { vol \%) }\end{array}$ & $\begin{array}{c}\text { Fiber } \\
(\text { vol \%) }\end{array}$ \\
\hline Control specimen & 24 & 76 & 0.0 \\
Dry spun & 23.5 & 76 & 0.5 \\
& 23 & 76 & 1 \\
Wet spun & 23.5 & 76 & 0.5 \\
& 23 & 76 & 1 \\
\hline
\end{tabular}

\section{RESULTS AND DISCUSSION}

\section{Flexural performance}

Figure 3 shows the flexural performance of the fibercement composite containing dry-spun fibers at $0,0.5$, and $1 \%$ volume fractions. It is evident that the acrylic fibers improved the maximum load bearing capacity of plain cement matrix. The maximum flexural stress decreased with an increase in the fiber volume fractions from 0.5 to $1 \%$. This behavior is due to the fact that mechanical performance of fiber reinforced cementitious composites depends on the distribution of fibers inside the matrix. In the specimen containing $1 \%$ fibers, there was a tendency to bundling and clumping of the fibers during the mixing process. Thereafter, this led to nonuniform distribution of fibers and decreases in fibers efficiency in cementitious composites.

In contrast to maximum flexural strength, the energy absorption capacity (surface area under loaddeflection curve) increased with the increase in fiber volume. The energy absorption has an important role regarding seismic loads and bending and/or shear loads. Figure 4 shows the flexural load-deflection behavior of the specimens containing wet-spun fibers at different volume fractions. Adding short fibers $(4-6 \mathrm{~mm}$ ) increased considerably both flexural strength and toughness of plain cement matrix.

Increasing the fiber volume content from 0 to $0.5 \%$ improved the energy absorption capacity by $18 \%$. It is evident that there is no change in flexural stress by increasing the fiber volume from 0.5 to $1 \%$. The flexural strength of composites with acrylic fibers at

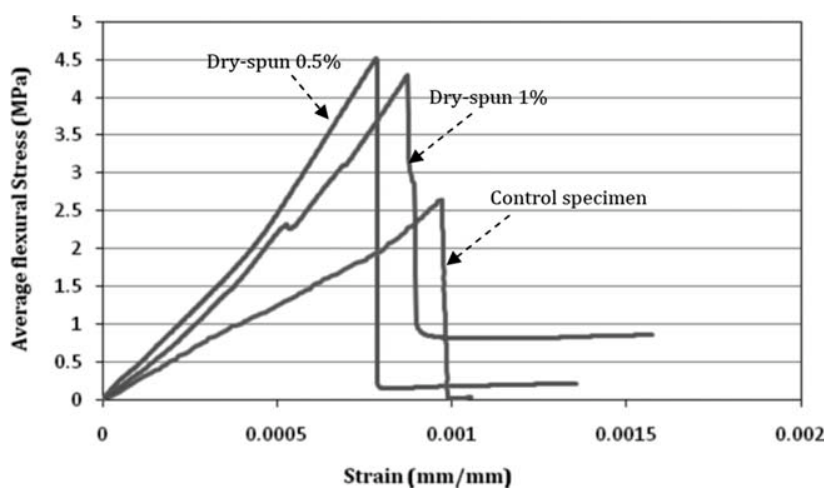

Figure 3 Average flexural performance of cement composites containing dry-spun fibers.

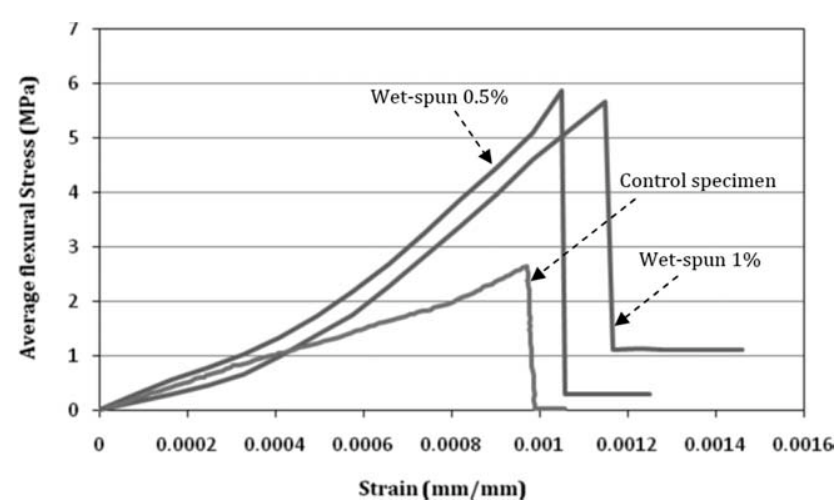

Figure 4 Average flexural performance of cement composites containing wet-spun fibers.

0.5 and 1 vol \% and respective value of standard deviation are presented in Table III. It is evident that composites containing wet-spun fibers show a better performance. Figure 5 presents energy absorption of composites containing both the investigated fibers. In the case of wet-spun fibers, it was concluded that the area under flexural curve was higher than composite containing dry-spun fibers; thereafter, this fiber leads to higher strain capacity and toughness for cementitious composites.

\section{SEM (Scanning electron microscopy) analysis}

The acrylic fibers have hydrophilic nature similar to cement paste, so during incorporation step of composite formation, good wetting occurred by the matrix. Thereafter, a remarkable adhesion occurred during composite formation between them. The SEM micrographs in Figures 6 and 7 reveal that both acrylic fibers covered perfectly with cement matrix. This postulated that there was a chemical adhesion between fibers and cement paste.

By consideration of SEM micrographs, it was possible to state that there is no significant difference in acrylic fiber chemical bonding to the cement matrix for both of them and shown a similar tendency to the cement paste. Thereafter, it can be concluded that the main objective in diversity of acrylic fibers efficacy in cement composites is introduced by phys$\mathrm{ical} / \mathrm{mechanical}$ bonding.

The bonding between fibers and the matrix is made up of two components: (i) chemical bonding; (ii) physical/mechanical bonding. As the chemical

TABLE III

Average Maximum Flexural Strength of Cementitious Composites Containing Wet and Dry-Spun Fibers

\begin{tabular}{ccccccc}
\hline & \multicolumn{2}{c}{$\begin{array}{c}\text { Fiber volume } \\
\text { content }=0.5\end{array}$} & & \multicolumn{2}{c}{$\begin{array}{c}\text { Fiber volume } \\
\text { content }=1\end{array}$} \\
\cline { 2 - 3 } Fiber type & Strength & S.D. & & Strength & S.D. \\
\hline Dry-spun acrylic & 4.36 & 0.14 & & 4.17 & 0.09 \\
Wet-spun acrylic & 5.87 & 0.17 & & 5.67 & 0.08 \\
\hline
\end{tabular}




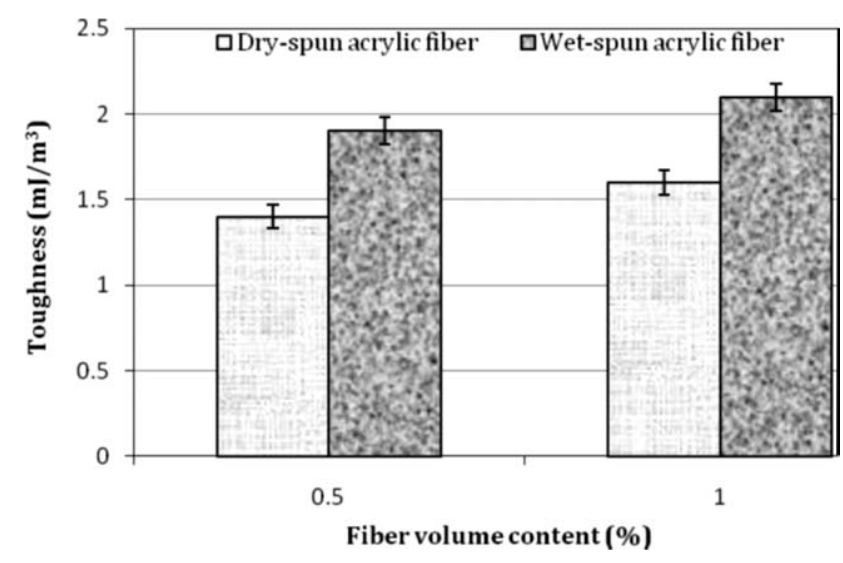

Figure 5 Energy absorption capacity as a function of fibers types and content.

structure of both fibers was the same, so, the differences in energy absorption of specimens should be attributed to different mechanical bonding (due to diversity in cross-sectional shape). To determine the effect of cross-sectional shape of fibers on the composite characteristics, they were geometrically simulated. Simple models were proposed using circles with equal diameter to simulate kidney-shaped and dog-bone-shaped fibers (Fig. 8).

These models have been used on the basis of visual comprehension of fibers cross-sectional shape to study their physical properties. To quantify the effect of fibers shape, it was decided to calculate the shape factor value for both acrylic fibers. To calculate the shape factor of dog-bone-shaped cross-section fiber, the proposed model in Figure 9(a) was obtained by an arrangement of circles with the same radius $(r)$ around them, as shown in Figure 10.

Determination of fiber's shape factor

Dog-bone-shaped model. Area calculation: To calculate the fiber cross-section area, a triangle $\mathrm{O}_{1} \mathrm{O}_{2} \mathrm{O}_{3}$ was drawn (Fig. 10). The cross-section was composed by an area of two circles (with radius of " $r$ ") and two almost triangle-shaped areas $\left(\mathrm{D}_{1} \mathrm{D}_{2} \mathrm{D}_{3}\right.$ and $\left.\mathrm{D}_{2} \mathrm{D}_{4} \mathrm{D}_{5}\right)$.

$$
\begin{aligned}
& \text { Circle area }=\pi r^{2} \text {; } \\
& \mathrm{O}_{1} \mathrm{D}_{1} \mathrm{D}_{3}=\mathrm{O}_{2} \mathrm{D}_{1} \mathrm{D}_{2}=\mathrm{O}_{3} \mathrm{D}_{2} \mathrm{D}_{3}=\frac{60}{360} \times \pi r^{2} ; \\
& \mathrm{O}_{1} \mathrm{O}_{2}=\mathrm{O}_{2} \mathrm{O}_{3}=\mathrm{O}_{3} \mathrm{O}_{1} \\
& =2 r \text {, so, Area of Triangle }\left(\mathrm{O}_{1} \mathrm{O}_{2} \mathrm{O}_{3}\right) \\
& =\frac{1}{2} \times 2 r \times \sqrt{(2 r)^{2}-r^{2}}=r^{2} \sqrt{3} \\
& \text { Area of } \mathrm{D}_{1} \mathrm{D}_{2} \mathrm{D}_{3}=\left(r^{2} \sqrt{3}\right)-3 \times\left(\frac{60}{360} \times \pi r^{2}\right)
\end{aligned}
$$

Finally, cross - section area $=2 \times$ Area of $\mathrm{D}_{1} \mathrm{D}_{2} \mathrm{D}_{3}$

$+2 \times$ Circle area;

$$
=2 \times\left(\left(r^{2} \sqrt{3}\right)-3 \times\left(\frac{60}{360} \times \pi r^{2}\right)\right)+2 \pi r^{2}=6.60 \times r^{2}
$$

Perimeter Calculation

As shown in Figure 10, the fiber cross-section perimeter was composed by the sum of arcs including $\mathrm{D}_{1} \mathrm{D}_{3}, \mathrm{D}_{4} \mathrm{D}_{5}, \mathrm{D}_{1} \mathrm{D}_{4}$, and $\mathrm{D}_{3} \mathrm{D}_{5}$. It is obvious that pairs of $\mathrm{D}_{1} \mathrm{D}_{4}, \mathrm{D}_{3} \mathrm{D}_{5}$ and $\mathrm{D}_{1} \mathrm{D}_{3}, \mathrm{D}_{4} \mathrm{D}_{5}$ are equal, and hence

$$
\text { Circle perimeter }=2 \pi r
$$

$$
\begin{gathered}
\operatorname{Arc} \mathrm{D}_{1} \mathrm{D}_{3}=\frac{60}{360} \times 2 \pi r ; \\
\operatorname{Arc} \mathrm{D}_{1} \mathrm{D}_{4}=2 \pi r-\left(\frac{120}{360} \times 2 \pi r\right) ;
\end{gathered}
$$

At the end, dog-bone-shaped cross-section perimeter

$$
\begin{aligned}
=2 \times\left(\frac{60}{360} \times 2 \pi r\right)+2 \times\left(2 \pi r-\left(\frac{120}{360}\right.\right. & \times 2 \pi r)) \\
& =10.47 \times r
\end{aligned}
$$

Kidney-shaped model. To calculate the shape factor of kidney-shaped cross-section fiber, the proposed model in Figure 9(b) was resulted by the arrangement
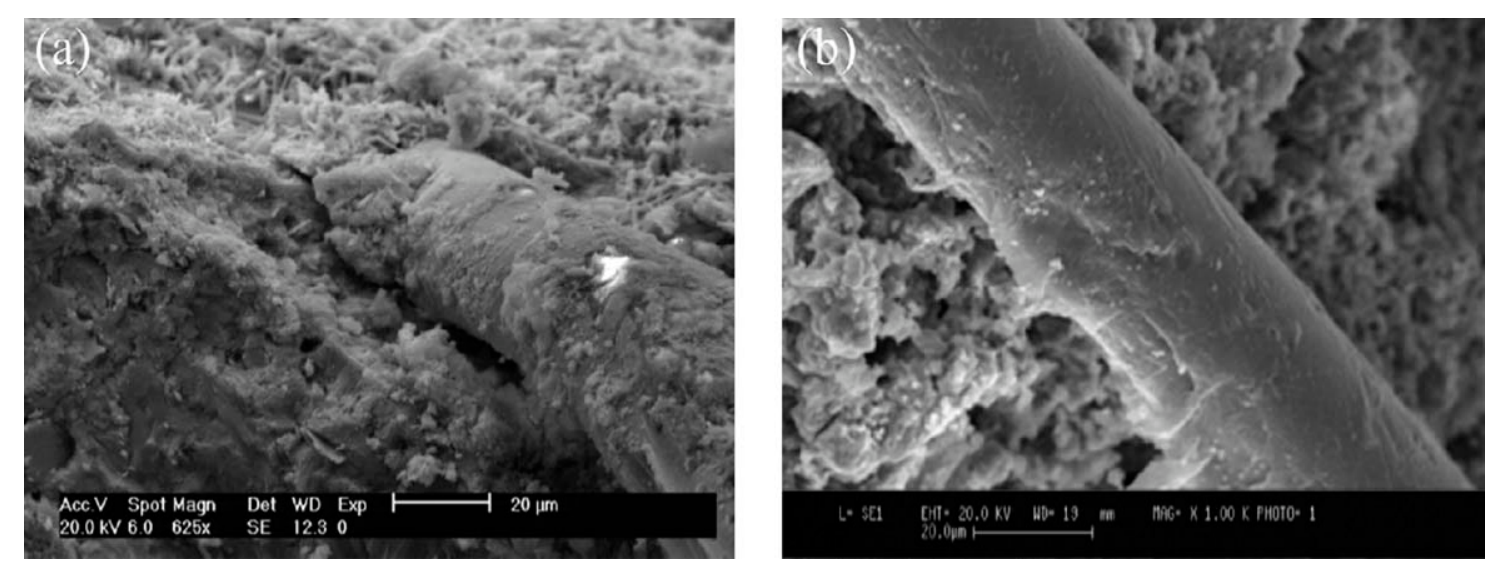

Figure 6 Acrylic fiber embedded in cement matrix; fiber surface covered by cement matrix: (a) wet-spun acrylic fiber and (b) dry-spun acrylic fiber. 

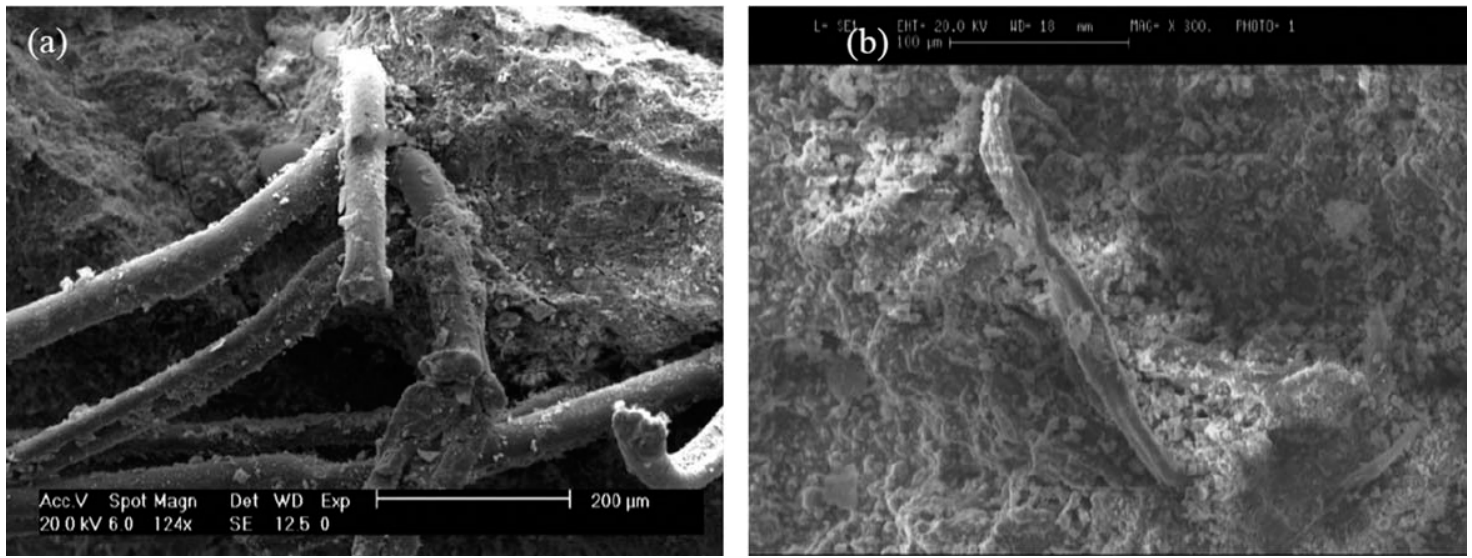

Figure 7 SEM micrograph of fracture zone of composite; (a) wet-spun acrylic fiber and (b) dry-spun acrylic fiber.

of circles with the same radius $(r)$ around them, as shown in Figure 11.

According to the kidney-shaped model (Fig. 11), the cross-section of area consists of an area of two circles and an area of dashed zone ( $D_{3} A B$ area).

Diameter of square $\left(\mathrm{O}_{1} \mathrm{O}_{2} \mathrm{O}_{3} \mathrm{O}_{4}\right)=\sqrt{(2 r)^{2}+(2 r)^{2}}$ $=2 r \sqrt{2}$;

Big circle radius $(\mathrm{CA})=r+r \sqrt{2}$;

Area of $\mathrm{CD}_{1} \mathrm{D}_{2} \mathrm{D}_{3}=\frac{1}{4} \times(2 r \times 2 r)-2 \times\left(\frac{1}{8} \times \pi r^{2}\right)$;

Area of cross-section

$=$ area of CAB-area of CD1D2D3 + area of one circle $=\frac{1}{4} \times \pi \times(r+r \sqrt{2})^{2}-\left(r^{2}-\frac{1}{4} \pi r^{2}\right)+\pi r^{2}=6.39 \times r^{2}$

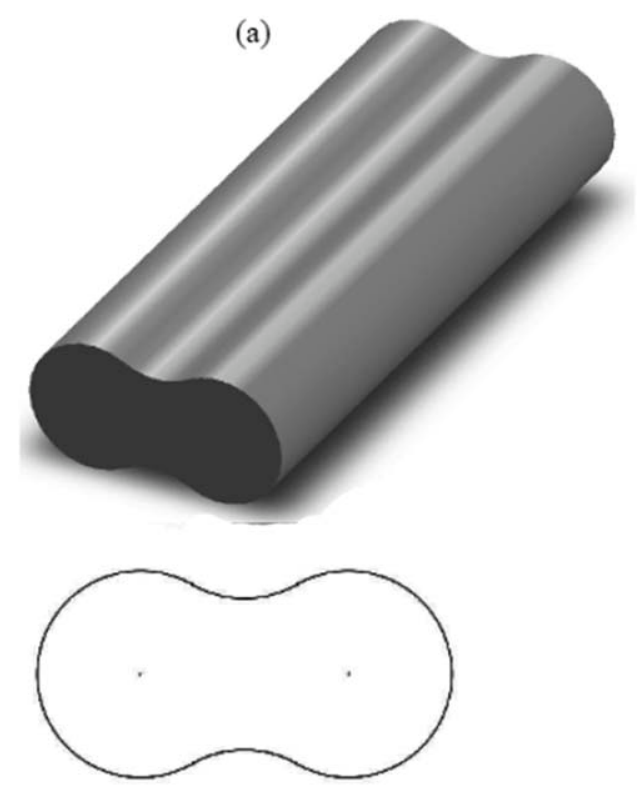

The perimeter of cross-section was calculated as follows:As illustrated in Figure 11, arc $\mathrm{D}_{1} \mathrm{D}_{3}=\operatorname{arc}$ $\mathrm{D}_{2} \mathrm{D}_{3}$, arc $\mathrm{D}_{1} \mathrm{~A}=\operatorname{arc} \mathrm{D}_{2} \mathrm{~B}$, the perimeter of kidneyshaped cross-section is the sum of length of two arc $\mathrm{D}_{1} \mathrm{D}_{3}$, two arc $\mathrm{D}_{1} \mathrm{~A}$, and arc $\mathrm{AB}$.

$$
\text { Arc } \mathrm{D}_{1} \mathrm{D}_{3}=\mathrm{D}_{2} \mathrm{D}_{3}=\frac{1}{8} \times 2 \pi r
$$

$\operatorname{Arc} \mathrm{D}_{1} \mathrm{~A}=\operatorname{arc} \mathrm{D}_{2} \mathrm{~B}=\frac{1}{2} \times 2 \pi r=\pi r$

$$
\operatorname{Arc} \mathrm{AB}=\frac{1}{4} \times 2 \times \pi \times(r+r \sqrt{2}) \text {; }
$$

Finally, the cross-section perimeter $=2 \times \frac{1}{8} \times 2 \pi r$

$$
+2 \times \pi r+\frac{1}{4} \times 2 \times \pi \times(r+r \sqrt{2})=11.65 \times r
$$

Based on the results obtained from cross-sections calculations, it is found that although the areas of

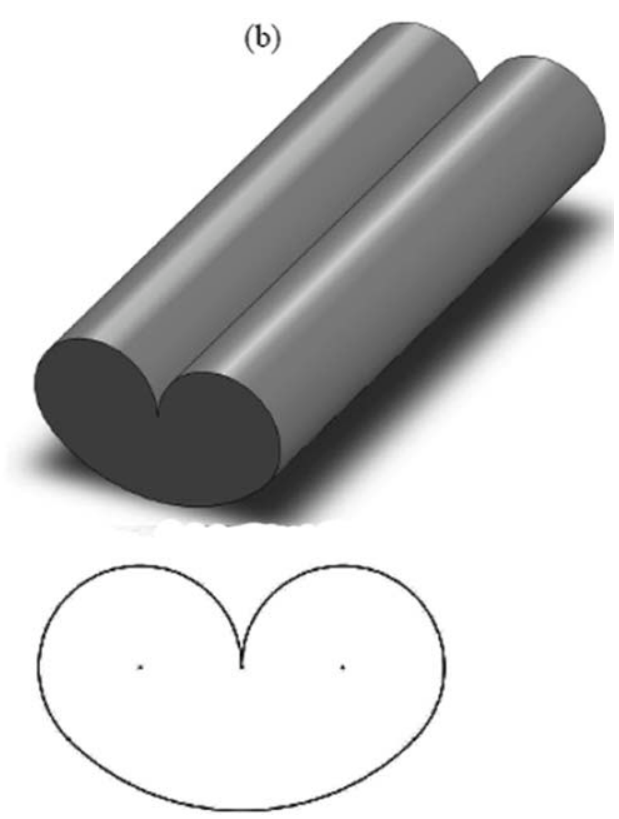

Figure 8 Proposed model of (a) dog-bone-shaped (dry-spun) cross-section and (b) kidney-shaped (wet-spun) crosssection. 

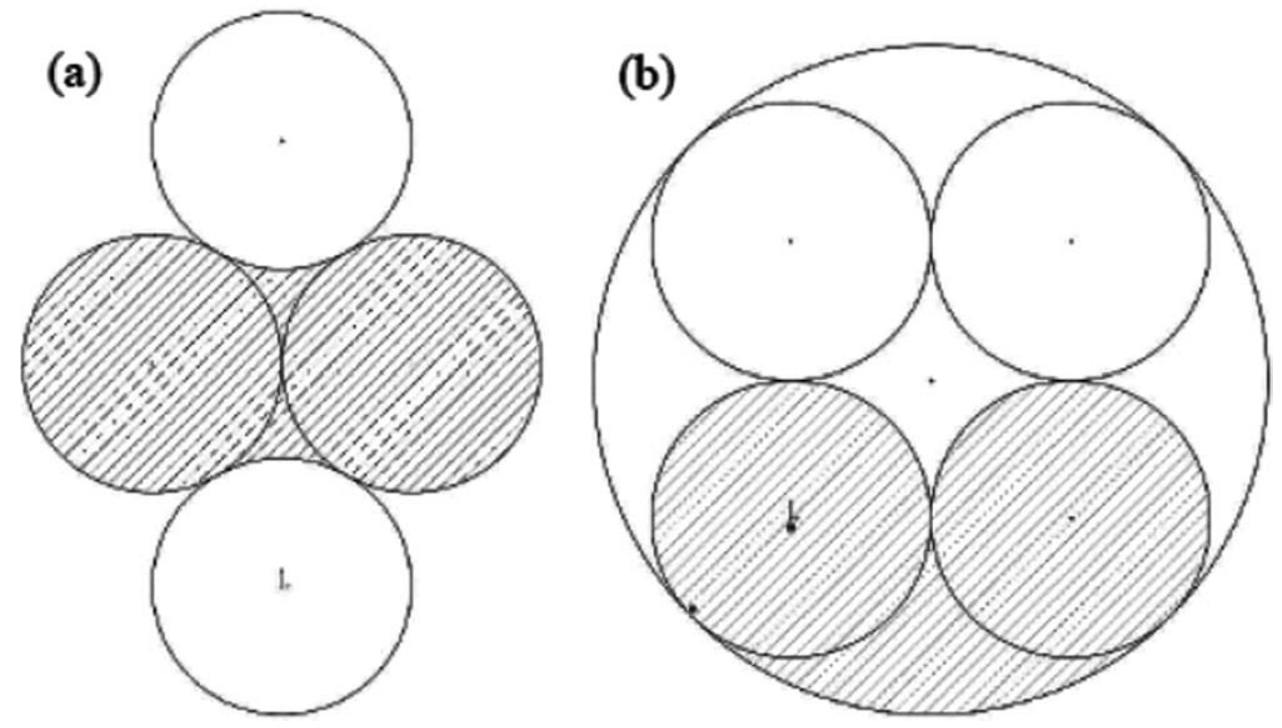

Figure 9 Model for simulation of (a) dog-bone-shaped cross-section and (b) kidney-shaped cross-section.

cross-sectional of two types of fibers are close to each other, their perimeters are different. The crosssection perimeter of wet-spun fiber was $11 \%$ higher than dry-spun fiber. This indicates that wet-spun fibers have higher lateral surface area compared with dry-spun acrylic fibers. To determine the shape factor, the perimeter of the same surface area of none-round cross-section was calculated, and the results are shown in Table IV. On the basis of these results, the shape factor was calculated as follows:

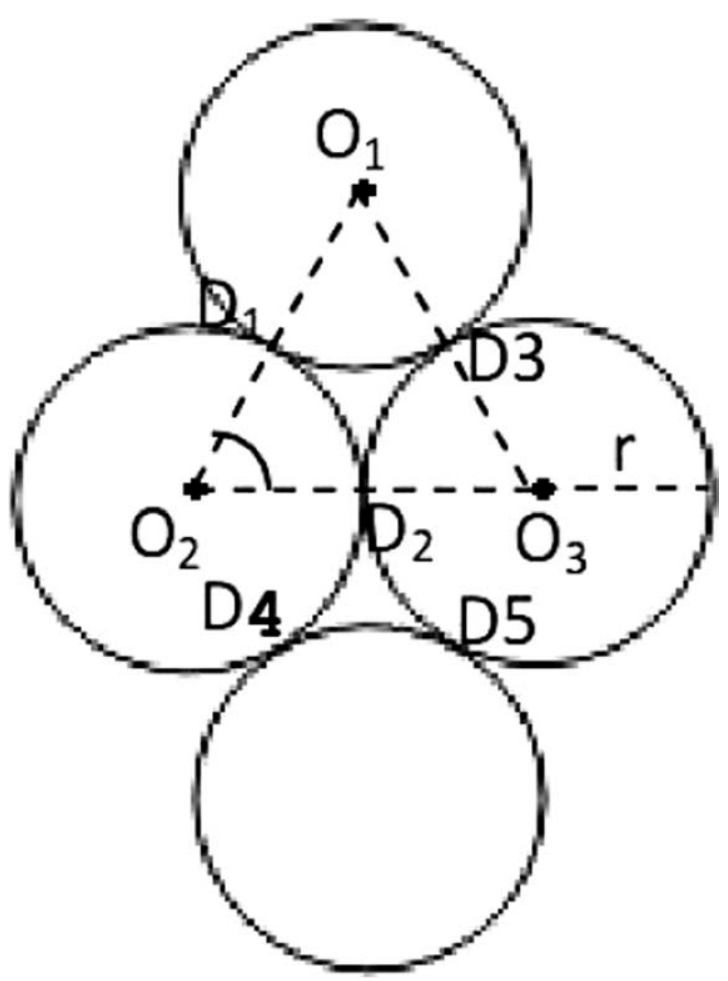

Figure 10 Schematic method for geometrical calculations of cross section in dog-bone-shaped fibers.
Determination of shape factor values for two types of fibers is given in Table III. Fibers with circular cross-sectional shape have a shape factor of 1 . The

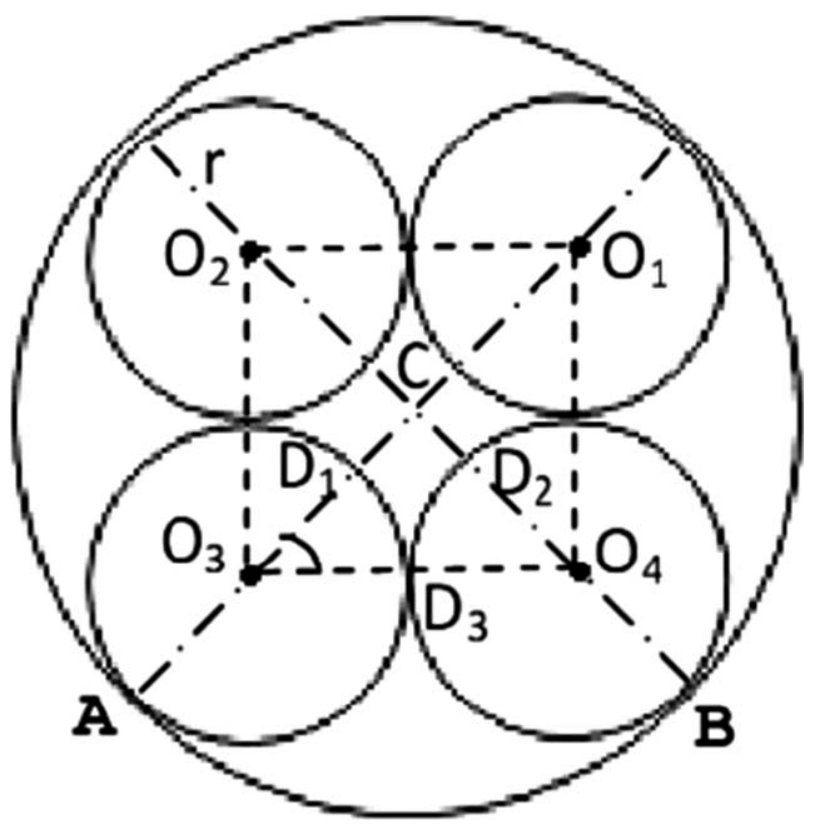

Figure 11 Schematic method for geometrical calculations of cross section in kidney-shaped fibers. 
TABLE IV

Fibers Shape Factor

\begin{tabular}{lcccc}
\hline Cross- & $\begin{array}{c}\text { Cross- } \\
\text { sectional } \\
\text { perimeter } \\
\left(P_{1}\right)\end{array}$ & $\begin{array}{c}\text { Perimeter } \\
\text { of circle } \\
\text { fiber with } \\
\text { equivalent } \\
\text { area }\left(P_{2}\right)\end{array}$ & $\begin{array}{c}\text { Shape } \\
\text { factor } \\
\left(P_{1} / P_{2}\right)\end{array}$ \\
\hline $\begin{array}{c}\text { Wet-spun } \\
\text { acrylic }\end{array}$ & $6.39 \times r^{2}$ & $11.65 \times r$ & $9.18 \times r$ & 1.3 \\
$\begin{array}{c}\text { Dry-spun } \\
\text { acrylic }\end{array}$ & $6.60 \times r^{2}$ & $10.47 \times r$ & $8.99 \times r$ & 1.16 \\
\hline
\end{tabular}

calculation shows that both fibers have a shape factor higher than 1 . The shape factor higher than 1 leads to a wider lateral surface area, which causes an increase in the contact area with the cement matrix. The wetspun fiber has a higher specific surface area than the dry-spun acrylic fiber. So, this study confirms that this type of fibers leads to enhance performance of cement composites. On the basis of the experimental results, higher shape factor prove that noncircular shape is better than round cross-sectional shape in terms of the mechanical properties of cement composites.

On the basis of stress-elongation response of flexural behavior of fiber reinforced cement composite as shown in Figure 12, two properties of interest may be obtained as following ${ }^{34}$ :

- $\sigma_{\mathrm{CC}}$, the stress at cracking;

- $\sigma_{\mathrm{PC}}$, the maximum postcracking stress.

However, $\sigma_{\mathrm{CC}}$ is primarily influenced by the strength of the cement matrix and $\sigma_{\mathrm{PC}}$ is attributed to the fiber reinforcing parameters and the fiber/cement matrix interface bonding. Therefore, improving the postcracking strength is a critical point to achieve a composite with excellent properties.

The values of $\sigma_{\mathrm{CC}}$ and $\sigma_{\mathrm{PC}}$ according to results are given in Table V. It is observed that with the introduction of acrylic fibers to the unreinforced cement matrix, the postcracking behavior generated. Furthermore, it can also be seen that the postcracking strength of cement mix containing $1 \%$ both types of acrylic fibers is higher than that of cement mix containing $0.5 \%$ acrylic fibers.

According to the results, the postcracking behavior of the cement composites increases by increase in the fiber content. As mentioned by Naaman, ${ }^{35}$ in the general way, the postcracking strength of compo-

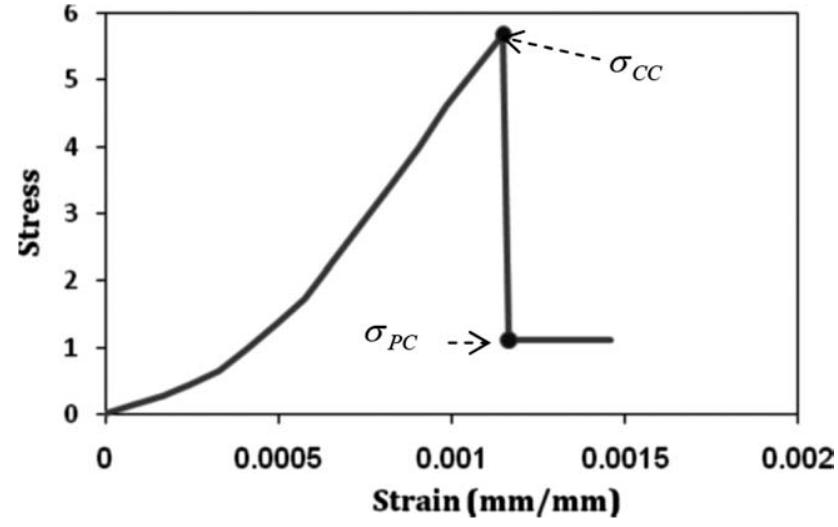

Figure 12 A typical flexural behavior of fiber reinforced cement composite.

sites, assuming the fibers crossing the crack are in a general state of pull-out, can be estimated from the following equation:

$$
\sigma_{\mathrm{PC}}=\frac{\Lambda}{4} \tau V_{f} \frac{\psi L}{A}
$$

in which $\tau$ is the bond strength at the fiber/matrix interface, $L$ is the fiber length, $V_{f}$ is fiber volume fraction, $\Psi$ is the perimeter of the fiber, $A$ is fiber cross-sectional area, and $\Lambda$ is the parameter which is corresponded to expected pull-out length, efficiency factor of orientation, number of fibers pulling out per unit area, snubbing coefficient, etc. ${ }^{35}$

By assuming the constant variable of $\Lambda, \tau, L$, and $V_{f}$, the estimated value of $\sigma_{\mathrm{PC}}$ depended to the only $\frac{\psi}{A}$ parameter. The increase in the estimated $\sigma_{\mathrm{PC}}$ strength of two proposed models acrylic fibers in comparison with their same area of circular fiber cross-section are given in Table VI.

The results shown that the wet-spun acrylic fibers (kidney-shape) may be have better performance in comparison with dry-spun acrylic fibers (doge-bone) cross-sectional shape compared with the circular shape.

It can be observed that for the same cross-sectional area, a kidney-shaped acrylic fiber is $27 \%$ more effective than a circular fiber, while a dog-bone acrylic fiber is $16 \%$ more effective. It can be concluded that experimental results for $\sigma_{\mathrm{PC}}$ shown well compatibility with expected postcracking strength for higher strength of wet-spun acrylic fibers compared with dry-spun acrylic fibers.

TABLE V

Average Stress-Strain Parameters

\begin{tabular}{|c|c|c|c|c|c|c|c|c|c|c|c|}
\hline & \multicolumn{3}{|c|}{$0 \%$ Volume fraction } & \multicolumn{4}{|c|}{$0.5 \%$ Volume fraction } & \multicolumn{4}{|c|}{$1 \%$ Volume fraction } \\
\hline & $\sigma_{\mathrm{CC}}$ & S.D. & $\sigma_{\mathrm{PC}}$ & $\sigma_{\mathrm{CC}}$ & S.D. & $\sigma_{\mathrm{PC}}$ & S.D. & $\sigma_{\mathrm{CC}}$ & S.D. & $\sigma_{\mathrm{PC}}$ & S.D. \\
\hline Wet-spun acrylic & 2.51 & 0.07 & 0 & 5.87 & 0.176 & 0.28 & 0.021 & 5.67 & 0.085 & 1.11 & 0.025 \\
\hline Dry-spun acrylic & 2.51 & 0.07 & 0 & 4.37 & 0.14 & 0.21 & 0.019 & 4.14 & 0.09 & 0.82 & 0.035 \\
\hline
\end{tabular}


TABLE VI

The Percentage Increase in the Estimated Value of $\sigma_{\mathrm{PC}}$

\begin{tabular}{lc}
\hline$\sigma_{\text {PC-dog-bone }} / \sigma_{\text {PC-circle }}$ & $16.46 \%$ \\
\hline$\sigma_{\text {PC-Kidney-shape }} / \sigma_{\text {PC-circle }}$ & $27 \%$ \\
\hline
\end{tabular}

\section{CONCLUSIONS}

In this investigation, cement composites with two kinds of acrylic fibers manufactured by the same company was studied. The fibers had the same chemical composition but differ in cross-sectional shapes (dog-bone and kidney shapes). The difference in cross-section occurred due to the spinning process. The following conclusions were obtained on the basis of the following results:

- The use of fibers even at low contents enhances the flexural strength and flexural toughness behavior of cement composites.

- Wet spun fiber (with kidney-shaped cross-sectional) leads to a high strength performance of cement composites.

- The shape factor of the fibers was modeled, and it was considered as a parameter, which influences the cross-sectional shape.

- The shape factor of wet spun fibers was higher than the dry spun one by a factor of $10 \%$. The increase in the shape factor caused a $26 \%$ and $23 \%$ improvement in flexural strength and toughness, respectively.

Apart from fiber geometry (longitudinal shape), cross-sectional shape of fibers have an important role in performance of fiber reinforced cementitious composites effects. The shape factor of the fibers can be a relevant parameter for the prediction of the performance of noncircular fibers in a cement matrix.

\section{References}

1. Wang, Y. Ph.D. Dissertation, Massachusetts Institute of Technology, 1989.

2. Bentur, A.; Mindess, S. Fiber Reinforced Cementitious Composites, 2nd ed.; Routledge, Taylor and Francis: UK, 2006.

3. Brandt, A. M. Cement-Based Composites, 2nd ed.; Taylor and Francis: New York, 2009.
4. Cotterell, B.; Mai, Y. W. Fracture Mechanics of Cementitious Materials; Chapman and Hall: New York, 1996.

5. Wörner, J. D.; Müller, M.; Proc. Int. Workshop High Performance Fiber Reinforced Cement Composites, Mainz, 1992; p 115.

6. Amat, T.; Blanco, M. T.; Palomo, A. Cem Concr Compos 1994, 31,16 .

7. Najm, H.; Naaman, A. F.; Chu, T. J.; Robertson, R. E. Adv Cem Based Mater 1994, 115.

8. Ogawa, A.; Horikoshi, T.; Hoshiro, H. Int J Restor Build Monument 2006, 12, 101.

9. Chen, P. W.; Chung, D. D. L. ACI Mater J 1996, 93, 129.

10. Kawamata, A.; Mihashi, H.; Fukuyama, H. J Adv Concr Technol 2003, 1, 283.

11. Bayasi, Z.; Zeng, J. ACI Mater J 1993, 90, 605.

12. Felekoglu, B.; Tosun, K.; Baradan, B. J Mater Process Technol 2009, 209, 5133.

13. Kurtz, S.; Balagru, P. Cem Concr Res 2000, 30, 183.

14. Song, P. S.; Hwang, S.; Sheu, B. C. Cem Concr Res 2005, 35, 1546.

15. Coutts, R. S. P. In Natural Fibre Reinforced Cement and Concrete, Ed. R. N. Swamy; Blackie: Glasgow, 1988.

16. Campbell, M. D.; Coutts, R. S. P. J Mater Sci 1980, 15, 1962.

17. Li, X.; Silsbee, M. R.; Roy, D. M.; Kessler, K.; Blankenhorn, P. R. Cem Concr Res 1994, 24, 1558.

18. Akers, S. A. S.; Garrett, G. G. J Mater Sci 1983, 18, 2200.

19. Williden, J. E. A Guide to the Art of Asbestos Cement; J.E. Williden Publ.: London, 1986.

20. Stucke, M. J.; Majumdar, A. J. J Mater Sci 1976, 11, 1019.

21. Proctor, B. A. J Mater Sci 1986, 21, 2441.

22. Xu, Y.; Chung, D. D. L. Carbon 2001, 39, 1995.

23. Mason, T. O.; Campo, M. A.; Hixson, A. D.; Woo, L. Y. Cem Concr Compos 2002, 24, 457.

24. Kim, D. J.; Naaman, A. E.; El-Tawil, S. Cem Concr Compos 2008, 30, 917.

25. Alhozaimy, A. M.; Soroushian, P.; Mirza, F. Cem Concr Compos 1996, 18, 85.

26. Atsushi, K.; Hirozo, M.; Hiroshi, F. J Adv Concr Technol 2003, 1, 283.

27. Park, S. J.; Seo, M. K.; Shim, H. B. Mater Sci Eng A 2003, 352, 34.

28. Wang, Y.; Li, V.C.; Backer, S. In: Proc. Mater. Res. Soc. Symp., Vol. 114, Pittsburgh, 1988, p 159.

29. Mobasher, B.; Li, C. Y. Adv Cem Based Mater 1996, 4, 93.

30. Singh, S.; Shukla, A.; Brown, R. Cem Concr Res 2004, 34, 1919.

31. Balagaru, A.; Shah, S. P. Fiber-Reinforced Cement Composites; McGraw Hill, Inc.:New York, 1992.

32. Aghanouri, A.; Zadhoush, A.; Haghighat, M. J Appl Polym Sci 2009, 111, 945.

33. Ziabicki, A. Fundamentals of Fiber Formation; Wiley: New York, 1976.

34. Naaman, A. E.; Reinhardt, H. W. High Performance Fiber Reinforced Cement Composites: HPFRCC 2; RILEM: London, 1996.

35. Naaman, A. E. J Adv Concr Technol 2003, 1, 241. 